\title{
An Analysis of Smart-Phone Industry in Bangladesh Using Porter's Five Forces Model
}

\author{
Mohammad Sayeedur Rahman', Busrat Jahan², Md. Al-Amin Nipu³, Shamsun Nahar4, \\ Mst. Nishita Aktar, ${ }^{4}$ Nadira Islam ${ }^{4}$, Mohammad Mobarak Hossain ${ }^{5}$, Md. Faizul Huq Arif6 \\ ${ }^{1}$ Department of Computer Science and Engineering, Bangladesh University, Dhaka, Bangladesh \\ ${ }^{2}$ Department of Computer Science and Engineering, Feni University, Feni, Bangladesh \\ ${ }^{3}$ Sonali Bank Ltd., Dhaka, Bangladesh \\ ${ }^{4}$ Department of Computer Science and Engineering, World University of Bangladesh, Dhaka, Bangladesh \\ ${ }^{5}$ Department of Computer Science and Engineering, Dhaka University of Engineering and Technology, Dhaka, Bangladesh \\ ${ }^{6}$ Department of ICT (DoICT), ICT Division, Dhaka, Bangladesh \\ Email:de.nayeem@gmail.com, hossenbipasa980@gmail.com, fuad031@gmail.com, shamsun_nahar@ymail.com, \\ nishita.akter@cse.wub.edu.bd, nadiraislamruku@gmail.com,mobarak3112@gmail.com, arifict27@gmail.com
}

How to cite this paper: Rahman, M.S., Jahan, B., Al-Amin Nipu, Md., Nahar, S., Aktar, Mst.N., Islam, N., Hossain, M.M. and Arif, Md.F.H. (2019) An Analysis of Smart-Phone Industry in Bangladesh Using Porter's Five Forces Model. Open Access Library Journal, 6: e5730.

https://doi.org/10.4236/oalib.1105730

Received: August 23, 2019

Accepted: September 13, 2019

Published: September 16, 2019

Copyright $\odot 2019$ by author(s) and Open Access Library Inc.

This work is licensed under the Creative Commons Attribution International License (CC BY 4.0).

http://creativecommons.org/licenses/by/4.0/

\begin{abstract}
Michael Porter's Five Forces Model is one of the most influential models for analyzing an industry's environment. This model helps a company to achieve its existence and success in an industry. This study contains an investigation of competitiveness of the Smart-phone industry in Bangladesh using Porter's Five Forces Model. Moreover, the investigation suggests new strategic directives to the new entrants, buyers and suppliers.
\end{abstract}

\section{Subject Areas}

Information Economics

\section{Keywords}

Five Forces Model, Smart-Phone Industry, Business Environment Analysis, Competitive Strategy

\section{Introduction}

For the new entrants who want to invest in any market, need to know the external environment using a standard tool. Porter's Five Forces analysis is a popular framework for analyzing business and marketing-based planning [1]. It is often regarded as a feasible and more practical alternative to the widely used SWOT analysis. The five key factors of Porter's model are used to identify the opportunities and risks. 
Porter's Five Forces Model is often used at the start of the development and review process in Electronic and Telecommunication industries. In Bangladesh, most of the new investors are interested to invest in Electronics and Software industry. However, their main focus is on Smart-phone as it is growing popular day by day to the Bangladeshi people. In addition, for the current fiscal year, Bangladeshi government put Value Added Tax (VAT) on Smart-phone imports to $15 \%$ and Advanced Income Tax (AIT) to $5 \%$ which made a total cost of importing Smart-phone to $20 \%$. This is extremely precarious for foreign companies. This will inspire the local manufacturers like Walton.

In this study, we have identified the competitive forces of Smart-phone industry those affect it the most in the perspective of Bangladesh. This literature review will help new entrepreneurs who want to establish their Smart-phone industry in Bangladesh.

\section{Methodology}

In this literature review, Porter's Five Forces framework has been used to analyze the environment of Smart-phone industry in Bangladesh. To realize the five forces for Smart-phone industry information have been collected from the secondary sources, like books, journal articles, newspapers and website publications. Then, significant relevant information has been analyzed to investigate the competitiveness of the Smart-phone industry. Finally, related factors have been categorized into the five forces.

\section{The Five Forces Model}

The Five Forces Model, developed by Michael. E. Porter is a composite of competitive forces in five areas of the overall market [2] [3]. This model can help a company understand the structure (internal and external) of its industry and stake out a position which is more profitable and less vulnerable to attack. This model is highly dynamic to analyze Electronic and Telecommunication industry. Figure 1 illustrates Porter's Five Forces Model.

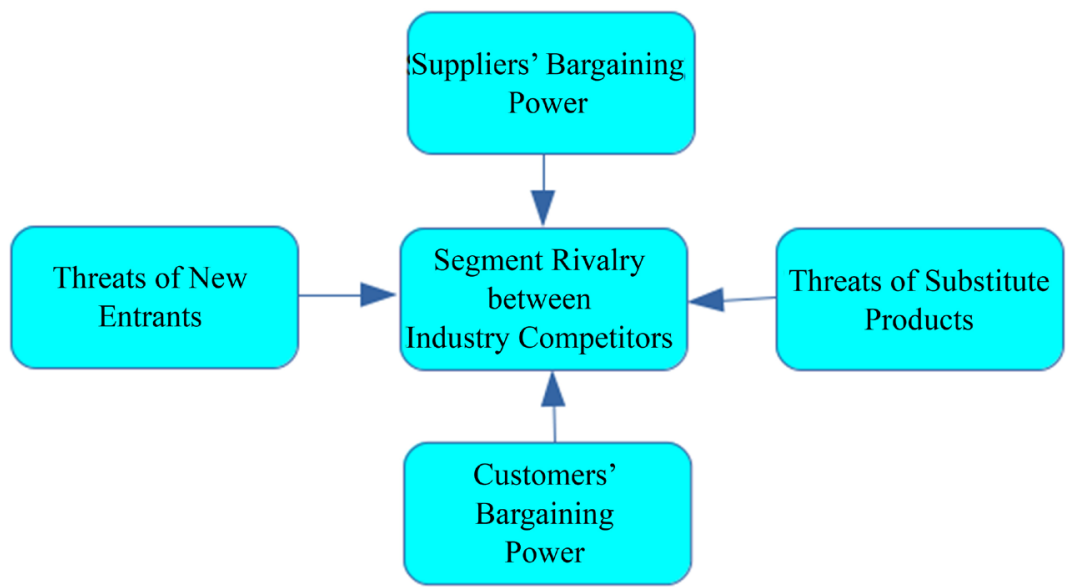

Figure 1. Porter's five forces model. 


\section{Recent Scenario of Smart-Phones Market in Bangladesh}

Like all other countries, the number of users of Smart-phone is on the rise in Bangladesh. Almost all leading brands of the world sells Smart-phones in Bangladesh, including Samsung, Nokia, Blackberry, Symphony, Oppo, LG and many more. Due to Bangladesh's low per capita income levels, nearly $80 \%$ of Smart-phone market is dominated by low-end handsets. However, People are always looking not only the price of Smart-phone but also its quality of touch screen, resolution of camera, Blue-tooth, Wi-Fi and many more. Therefore, the companies which provide high configured Smart-phone with low cost are more attracted by the customers.

Smart-phone market of Bangladesh has been captured almost fully by the Chinese products which offer cheaper price and attractive outlook. China has successfully created a greater portion of Smart-phone market in Bangladesh by providing cheaper low-end Smart-phones with high-tech features. According to National Board of Revenue (NBR), in July-December 2015, 96.46\% of the total imported handsets came from China. According to CyberMedia Research (CMR) 2014, Symphony was dominating 53\% of the market in Bangladesh.

The recent market scenario shows, most of the brands of Smart-phone in Bangladesh followed downward trend in prices to maintain a competitive edge. Therefore Smart-phone is growing popular to all classes of people. The growing demands of Smart-phone in recent years suggest that the prospect of Smart-phones in Bangladesh is very high.

\section{Determining Porter's Five Competitive Forces of Smart-Phone Industry}

The Smart-phone industry has comprised of a club of big national and foreign manufacturers. It has become a crucial fact to identify the five forces for the Smart-phone industries of Bangladesh. A Five Forces analysis of Smart-phone markets of Bangladesh has been carried out in this section.

Figure 2 shows an abstract view of five forces for Smart-phone industry in the perspective of Bangladesh.

\subsection{Buyers' Bargaining Power}

In the Smart-phone market, the customers' bargaining power is rising because of the increasing number of choices in the Smart-phone industry. Apart from that, customers have all required information so that they can bargain effectively. In Bangladesh, there are different types of Smart-phones at different prices. However, low-end Smart-phones like Symphony, Walton, Micromax are popular here. Recently, some leading brands of the world like Huawei, Samsung, LG, Sony, Nokia started supplying Smart-phones in Bangladesh with low prices. This is because the number of opportunities to switch from one product to another is becoming higher and customers have lot of bargaining power in Bangladesh. 


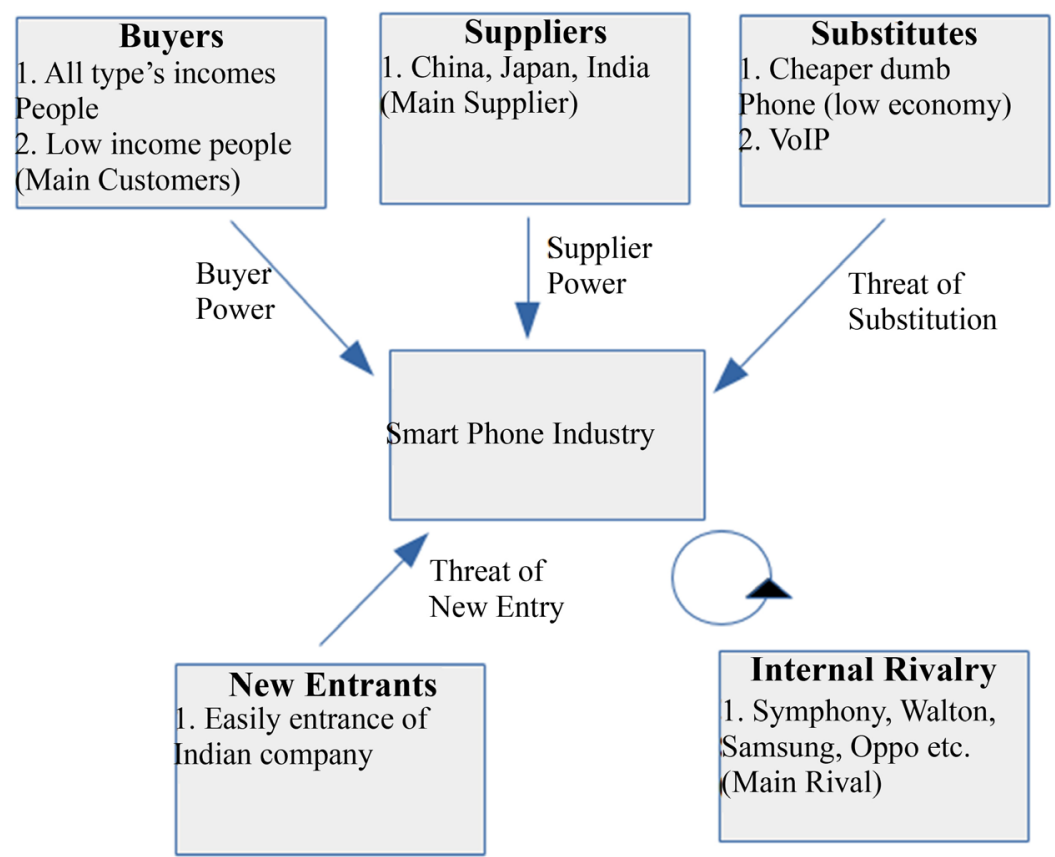

Figure 2. Michael porter's five forces model: adapted for Smart-phone industry in Bangladesh.

\subsection{Supplier's Bargaining Power}

The bargaining power depends on the brand name, size of the company as well as the strategic importance of the supplies. In Bangladesh, in particular South Korea, Taiwan, China and Japan have a great influence in hardware market. Their main customers are low-income people and some high-income people. Therefore, there is intense competition to reduce the prices of their products. Recently robust technology played an important role in the Smart-phone market. Therefore, the bargaining power of suppliers in the Smart-phone industry is moderate to weak.

\subsection{Threats of New Entrants}

There are always possible threats of new entrants in Smart-phone industry. Indian companies like Oppo, Intex, Lava easily enter in the Bangladeshi Market. In spite of that, in Bangladesh these threats of new entrants are medium. One of the reasons behind that is the customer loyalty towards existing brands. Smart-phone industries in Bangladeshi market have created significant brand positioning and target segment on income categories people. Moreover, advanced technologies make it difficult for new entrants in the market, because they have to develop those technologies before effectively competing. Apart from that, Bangladeshi government has imposed a huge tax on handset from import can also make difficult for the new entrants.

\subsection{Degree of Rivalry}

The degree of rivalry depends on some factors: similarities of companies, com- 
petitor size, number of players, low-cost switching, level of differentiation, etc. In Bangladeshi market the rivalry among existing Smart-phone companies is very high. Most common reasons are the Smart-phone industry is dynamic by nature with short product life cycles, consumers' tastes are changing. In most cases, customers are switching to superior packages which add better value in services. Symphony, Samsung, Walton are leading this industry and they are in an advantaging than other competitors.

\subsection{Threats of Substitutes}

Presence of substituted product is a great threat for the survival of a business organization. Threat of substitutes in the Smart-phone market of Bangladesh is very low. Now Internet is available in Bangladesh. People can easily call abroad through Internet protocol with low price which is called Voice over Internet Protocol (VoIP). Apart from that, only for calling purpose cheaper dumb handset is a good substitute of Smart-phone. However, due to advancement of new features and applications Smart-phones are growing popular. In Bangladesh, low-income people choose cheaper low-end phone and high-income people choose high-end phones. The existing companies are trying to give cheaper price of phones with high configuration.

\section{Conclusion}

According to the overall discussion, it is clear that the strongest competitive force of the Smart-phone industries in Bangladesh is the rivalry among competitors. However, customers' bargaining power and threats of new entrants have also significant impacts.

\section{Conflicts of Interest}

The authors declare no conflicts of interest regarding the publication of this paper.

\section{References}

[1] Ketels, C.H. (2006) Michael Porter's Competitiveness Framework-Recent Learnings and New Research Priorities. Journal of Industry, Competition and Trade, 6 115-136. https://doi.org/10.1007/s10842-006-9474-7

[2] Porter, M.E. (1980) Competitive Strategy: Techniques for Analyzing Industries and Competitors. The Free Press, Harvard Business Publishing, New York.

[3] Thompson, A.A., Strickland, A.J. and Gamble, J.E. (2007) Crafting and Executing Strategy: The Quest for Competitive Advantage: Concepts and Cases. 15th edition, McGraw-Hill Irwin Publisher, New York. 